\title{
Seismic risk and conservation of architectural heritage in the Mediterranean basin
}

\author{
S. D’Agostino \& M. Bellomo \\ Centro Interdipertamentale di Ingegneria per i Beni Culturali \\ dell'Università "Federico II", Napoli, Italy
}

\begin{abstract}
The architectural heritage which has accumulated over thousands of years in the Mediterranean basin comprises a rich and complex record of the history of successive civilizations, embodying their long, intricate development. This heritage suffered considerably from the upheavals which characterised last century, and its conservation represents a major cultural commitment. While the Mediterranean basin as a whole has always been at great risk from seismic events, the ancient conception of building never failed to take this hazard into account. The advent of modern "structural engineering" based on a technicalscientific approach to construction has led to calculation of seismic risk for new constructions and the formulation of complex norms. Regrettably, seismic engineering has not paid sufficient attention to the historic built environment, and the few indications which are to be found in official regulations are confused and contradictory. There are problems concerning private property, as well as of access, safeguarding and structural modifications. This has led to interventions which are totally out of keeping with the ancient conception of building in monuments, and a widespread, deleterious cementification of the historic built environment. This has profoundly altered the nature of ancient monuments as documents of material history. In the last twenty years some researchers have sought to contrast this technocratic approach, particularly in Italy, where the concept of "structural improvement" has been elaborated to safeguard historic buildings and contexts. In this paper we first illustrate the damage done to some exemplary monuments, and go on to examine the inadequacy of current regulations, suggesting a simple approach to anti-seismic safeguarding for ancient architecture. We refer briefly to a series of important cases where it has been possible to apply the criteria elaborated and adopted by the Italian Ministero dei Beni e delle Attività Culturali. We end by outlining the great difficulties caused by current trends in the economy for a compatible conservation of the built heritage.
\end{abstract}

Keywords: seismic risk, conservation architectural heritage. 


\section{Seismic vulnerability and the built heritage}

All the civilizations which succeeded each other over thousands of years and laid down stratifications in the Mediterranean basin built their monuments according to a conception of building which took seismic risk into account, in view of the morphological character of the territory. Evidence for this lies in the numerous examples of ancient architecture which for many centuries have withstood recurrent seismic episodes, registering damage which has invariably been compatible with their state of conservation. It must be said that such damage is always in direct proportion to the lack of maintenance characterising the historic artefact. The ancient built heritage constitutes the most emblematic feature of human memory and progress as an integral component in the historical extension of human presence on the territory. Its conservation involves the material culture of the monument and hence its conception. Unfortunately the mechanical approach to construction, with only rare exceptions [1], has not drawn on the scientific knowledge contained in those "rules of the art" which enabled successive civilizations to construct an architectonic heritage of great beauty and complexity through an expert use of the natural materials available locally. On the contrary, it has sought to interpret the ancient building conception through an a-critical transposition of structural analytic models proper to modern construction science. This attitude, as we shall see in more detail below, has actually increased the vulnerability of the ancient buildings. In Italy, thanks to an interdisciplinary approach combining structural engineering with an awareness of historical culture, we have been working for years on identifying more appropriate models for evaluating the seismic vulnerability of the monumental heritage, making a distinction between its intrinsic and extrinsic aspects [2].

\section{Deterioration caused by human factors}

For more than two centuries Western culture has attributed to our cultural heritage the value of historical evidence, and has recently come to see buildings and heritage sites in the dual light of a monument-document [3], constituting the archive of the material history of humankind [4]. Recognition of their integrity as historical documents establishes them as a permanent resource for scientific research. Unfortunately, however, in spite of the paramount theoretical grounding of these axioms, humans continue to act in the most ill-considered fashion, forcing us to point to anthropic vulnerability as the greatest single cause of destruction of our heritage in general, and of historical buildings and sites in particular. In some cases human factors act in a sensational fashion, but they generally lead to deterioration over time, causing much greater damage than can ever be attributed to seismic vulnerability.

In fact, in the numerous conflicts taking place across the planet, man-made violence rarely spares a monument. Thanks to the destructive power of modern weaponry, the 20th century saw destruction on a devastating scale, notably in Europe, as well as acts of cultural terrorism and widespread vandalism. Serious 
damage is also caused by prolonged periods of abandonment, which may lead to states of deterioration that exceed the damage produced by recurrent seismic events, and also by new, incongruous modes of use. In addition to the brutality deriving from voracious economic and political interests we have to denounce the widespread practice of consolidation which has led, and will continue to lead, to major damage in the architectonic heritage. Not only does it distort the original construction conception, but also wholesale cementification causes deterioration in the traditional building materials. Moreover the practice of adopting materials which are technologically advanced but often incompatible with the ancient materials results in structures with a very limited durability compared with the lifespan of monuments of antiquity.

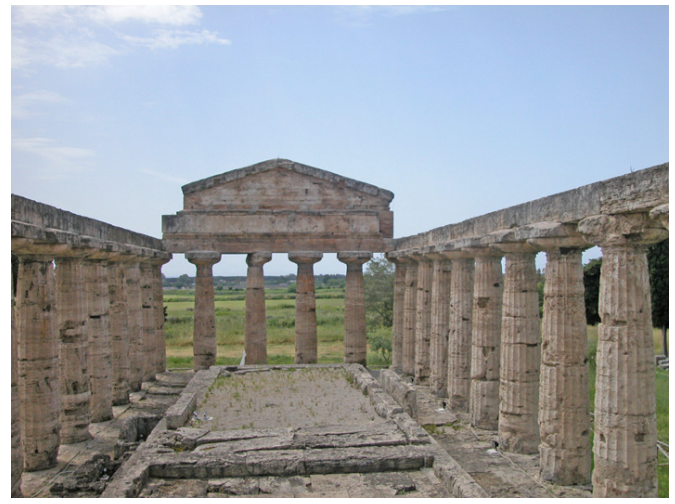

Figure 1: $\quad$ Paestum, Temple of Cerere.

\section{The myth of security and widespread cementification}

Scientific progress has produced a high standard of living in Western society, yet in spite of the alleged globalization of the world system, most areas of the planet still endure very harsh living conditions. Technological progress has given the most industrially advanced nations a sense of omnipotence, but also a great need for security. As a result Westerners feel particularly insecure when it comes to events and phenomena, whether exceptional or not, such as episodes of natural vulnerability and seismic events in particular. There is a widespread demand for protection from seismic risk which has led scientists to draw up complex models of calculus for new constructions, while largely failing to investigate the problems linked with conserving the existing heritage. The immense amount of building that has gone on worldwide since the middle of the 20th century, involving structures in reinforced concrete, was put up almost everywhere, and particularly in Italy, according to anti-earthquake protocols, and in fact it has generally withstood a series of seismic events. But these buildings are now heavily compromised by the poor quality of the materials used, and show clear signs of a very short lifespan compared to that of the built historical heritage. Furthermore structural engineering, lacking experience of studying ancient 
buildings, has used crude technologies and invasive adjuncts in reinforced concrete to provide the ancient buildings with a rough and ready stability, ignoring a constructive know-how which had guaranteed the existence of this architectonic heritage for centuries.

Italy saw some exemplary cultural campaigns during the 1980s, involving departments of the Ministero per i Beni Culturali in drawing up ground-breaking documents and undertaking important research projects [5]. Yet unfortunately, notwithstanding the formal declarations of principle, the practice of planning and consolidation continues to ride roughshod over the construction conception of the architecture of the past. What is more this approach, both unsuitable and inadequate, has spread throughout all the Mediterranean basin, irreversibly compromising the integrity of such outstanding monuments as the complex of the Acropolis in Athens and the temples of Ancient Egypt [6]. (The restoration under way since 1975 of the Acropolis in Athens is designed in part, so far as is possible, to rid the monuments of the invasive cement adjuncts. There it was possible on account of the original material used, whereas similar interventions are still not practicable in the temples of Magna Grecia.)

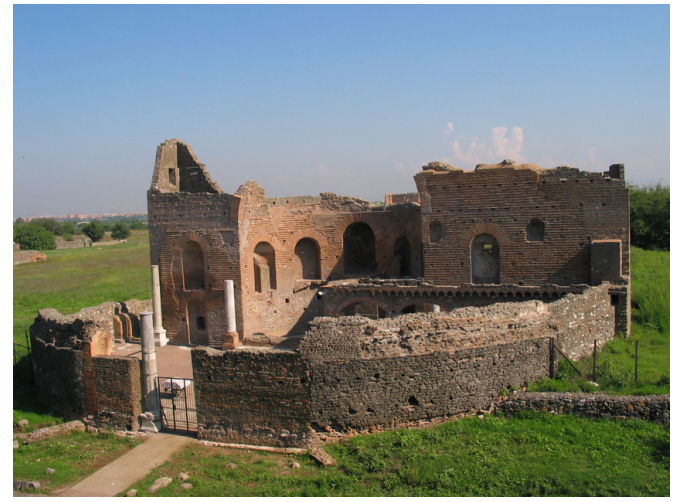

Figure 2: $\quad$ Rome, Ninfeo of Villa dei Quintilii.

\section{Seismic improvement and the impact of regulations}

It was in fact the theoretical elaborations pursued in the Ministero dei Beni Culturali with the scientific collaboration of numerous specialists which led in Italy to the concept of seismic improvement. This is based first and foremost on the historical fact of the intrinsic capacity of much of the built heritage to withstand frequent seismic events over the centuries. This leads to the awareness that the overall construction conception of the ancients involved adequate and implicit security coefficients which in practice safeguarded the buildings in terms of local seismic vulnerability. This affected the design of buildings in terms of volume and geometry, the quality of the materials used, and their assemblage using adequate techniques. The fact is that every ancient construction was a unitary organism in which the structural function was 
omnipresent. The building was conceived to meet numerous requisites, contemporaneously and in parallel, including those of statics. At the same time, however, an ancient building is often the victim of alterations and even more of systematic periods of deterioration: hence the necessity of "improving" its static performance. Such improvement can only be planned once the construction conception which lies behind the ancient structure has been fully understood, any alterations have been thoroughly examined, and the causes and state of current degradation have been properly established. Obviously an ideal improvement intervention would be one that restores the building to its original state, but this is rarely possible, even without considering the slow but inexorable ageing of the construction materials. Once however this parameter of improvement has been adopted as a touchstone, the expert is left with the complex task, within the framework of inadequate and incongruous norms, of coming up with the best improvement intervention possible, by which we mean not invasive, respecting the ancient construction conception, employing natural materials, and not forcing the architectonic monument into the straitjacket of static performance elaborated by modern structural engineering [7].

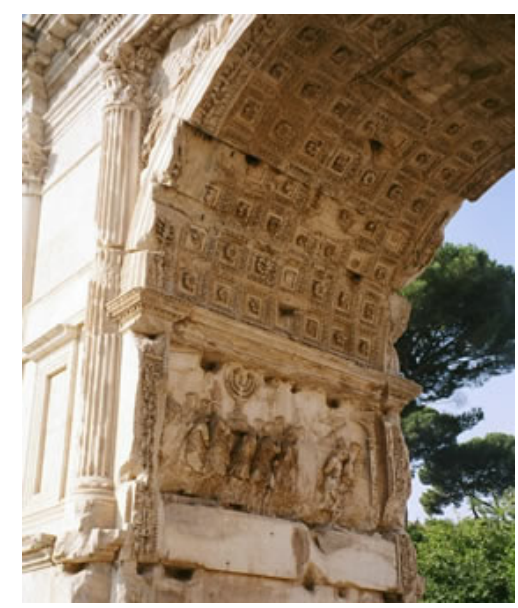

Figure 3: $\quad$ Rome, Arco di Tito.

The concept of improvement has been remarkably successful in Italy at the theoretical level. It has been adopted by the Ministero per i Beni Culturali, and included in the definition of the restoration of property in the recent norms on safeguarding [8]. Thus it is also recognised by the official safeguarding bodies charged with approving projects. In addition the concept of improvement is part and parcel of the current norms on seismic vulnerability, which emphasises its application in accordance with the principles of conservation. Unfortunately however there is still a yawning gap between the culture of improvement and the standard practice of consolidation in both technical and commercial terms. This practice continues to violate the ancient fabric, in complete ignorance of its characteristics and resources. Regrettably geotechnical and structural advisers 
have not realized what a great cultural resource improvement offers. With the complicity of contractors who still ignore the requirements of correct constructive restoration, they continue to oversee the systematic destruction of the material history of ancient architecture throughout the Mediterranean basin. Both in Italy and in Europe at large seismic regulations have been introduced based on a logic which corresponds entirely to modern structural engineering, penalising new constructions in masonry and even more the existing construction fabric. The most stark example of this in the Italian context concerns the residential buildings dating from the 19th century which characterise the historical centres of all the major European cities. On one hand they are in breach of the regulations because buildings in masonry are not permitted to exceed 16 metres in height, even for the lowest coefficients of seismic vulnerability. On the other hand this prestigious architectonic heritage, with an immense real estate value, does not once merit an explicit reference, even though the regulations are supposed to be strictly binding on all existing constructions.

\section{Case studies}

Ensuring a constructive conservation in keeping with the value of the monument as a historical document of the archive of material history is a complex matter. There is undoubtedly greater awareness of it in the culture of archaeology than in that of the history of architecture. On one hand the latter is not very aware of the values of material history, and on the other it is too conditioned by the culture of design, which all too often seeks to use the historical building as if it were an artificial natural phenomenon on which to intervene in all liberty. This is why in what follows we refer above all to examples drawn from ancient architecture.

Among the specimens of temple architecture bequeathed to us by Magna Graecia the three temples at Paestum are outstanding in their magnificence and integrity. In the early years of the 19th century they were subjected to a very limited conservational restoration which respected the original architectural values. Then in the 1960s the temple of Athena was the object of one of the first interventions of cementification and pinning using steel bars, fortunately restricted to the façade of the temple facing the hills. A comprehensive conservational restoration of all three temples has just been completed. During its course, a determined effort was made to ensure that the concept of improvement prevailed, avoiding any thoughtless intervention of so-called "seismic upgrading" for constructions which without any maintenance at all have withstood the seismic vulnerability of this territory for all of 25 centuries. A general report on the restoration is due to appear in print shortly [9].

With respect to ancient Pompeii, everyone knows of the state of endemic degradation in which it has languished since the mid-20th century. The scant funding earmarked for maintenance and restoration can at best serve to overcome the most urgent emergencies for the ancient fabric, subjected to the frenetic assault of tourists. At the end of the 1970s the situation was considerably worse than it is today, and the seismic events that occurred in 1980-81 caused a drastic worsening of the situation, so that the site had to be temporarily closed. In such 
cases the criterion of improvement suggests restoring the ancient masonry using the same materials and techniques with which it was originally built, making any integrations clearly visible. Unfortunately however the experts of the moment decided to apply braces to walls of even moderate height belonging to the fabric of the "insulae". In several cases this led to the ancient document being definitively altered with the application of "reinforced bracing". The same fate befell most of the columns, which were brutally pinned. Twenty years on the oxidization of the metal bars has led to a state of ruin which is almost impossible to reverse [10].

With great good fortune it is only recently that Italian seismic regulations have classified the territory of the city of Rome as seismic. Thus, at least for the more far-sighted culture of archaeology, it has been easier to impose the criterion of improvement which, apart from seismic action, provides appropriate guidelines for structural conservation. Needless to say there are also projects for the "seismic upgrading" of the Colosseum itself! In the case of Villa dei Quintili, which is currently the largest complex of Roman architecture undergoing excavation and restoration, it has been possible to apply the criterion of improvement and minimal intervention. The ancient constructive conception has been fully respected, avoiding misguided consolidation, using traditional materials and techniques without integrations. Identical criteria have been followed in the recent restoration of the Arch of Titus on the Palatine, and in Castello Caetani, part of the complex of the Mausoleum of Cecilia Metella on the Appia Antica [11].

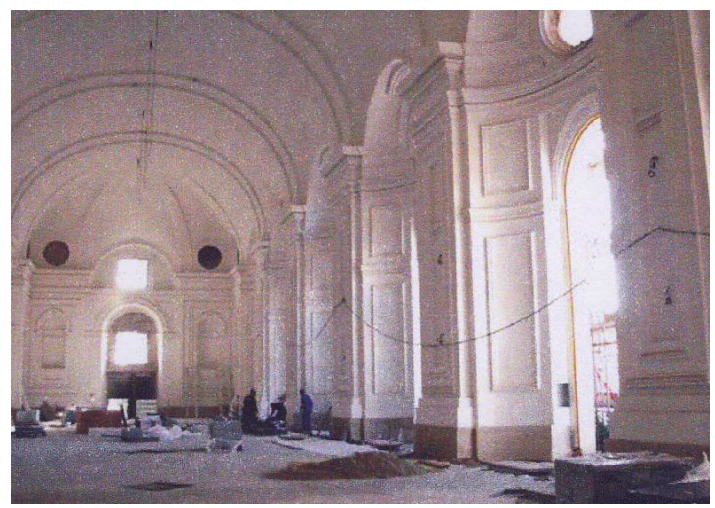

Figure 4: Turin, Venaria Reale, "Citroniera" seen from inside.

Turning to modern historical architecture, the criteria of improvement and minimal intervention have been applied in the project of restoration and enhancement of the complex of Citroniera-Scuderia built by Filippo Iuvarra in the Regia Sabauda of Venaria Reale in Turin [12]. In both this case and at Castello Caetani the introduction of modern construction elements which do not alter the construction performance of the ancient building, and which were required in the interests of enhancement of the monument, was carried out in a 
manner which is entirely reversible, fully respecting the monument itself and possible future revisions that may ensue as our historical culture progresses.

As we mentioned above, a special case is represented by the large-scale residential building put up in the 19th century in the historical centres of all the major European cities and the Mediterranean basin. This fabric is the object of superficial safeguarding regulations, more often than not ignored, concerning at most the integrity of storeys and volumes and the decorative elements, while they simply ignore the conservation of the construction conception. No explicit reference is made in Italian seismic regulations to this major architectonic category, whereas surely this is an exemplary case for imposing the criterion of improvement, drawing up proper diagnostic protocols and obliging the technical experts to take full responsibility for seismic security. Unfortunately this will be possible only once a widespread culture of conservation has taken root, based on both historical knowledge and technical and scientific data. This culture will recognise in the conservation of the material fabric of historical centres throughout Europe and the Mediterranean basin an absolute value for the very survival of the identity of the Western world.

\section{The difficulties of a compatible conservation}

There are still many difficulties at a technical and administrative level in ensuring conservation of the historical heritage in line with the principles set out above. The first concerns the reluctance at this level to confront a historical culture. What is lacking is any notion of an interdisciplinary strategy. This is surely the only explanation for the aridity and incoherence of many regulations which take no account of the historical built heritage. Then there is the deeprooted failure on the part of building contractors to specialise in the conservation of this heritage, penalised by an overly technological attitude. For them too a well-grounded specialisation in the field of conservation, drawing on traditional materials and the retrieval of an illustrious tradition of craftsmanship able to exploit know-how accumulated down the centuries, could prove just as profitable as it has in the sphere of art conservation. There is currently no legal obligation to ensure programmed maintenance of the built heritage, meaning that recent seismic events have all too often affected a heritage which was degraded and hence much more vulnerable. At the same time it is standard practice to make the community foot the bill for damage inflicted on this heritage and the environment by natural calamities, although such damage is in part due to inadequate conservation. We must end by drawing attention to the fact that here in Italy the whole system for safeguarding cultural resources is in crisis. At the moment we risk losing a grand cultural tradition which for over two centuries has stood as a fundamental point of reference for a compatible conservation [13].

\section{Conclusions and prospects}

All of these elements go to form an undeniably gloomy picture for the future of the matchless architectonic heritage of the Mediterranean basin. It is important to 
highlight the problems, in the hope that the prevailing technical and scientific culture will come to recognise the symbolic value of the monument-document as the guiding light for conservation which is compatible with the requisites of historical knowledge.

Reflecting upon the preservation of architectonic heritage of the Mediterranean basin, we have seen the essential role that engineering is called upon to play. The outlined criteria and intervention strategy lead to a design concept which, by fully respecting the ancient works that have come down to us, aims to avoid any alteration of the structures based on a mistaken view of safety, as regards both seismic vulnerability and also the type of preservation desired. This design concept recognises that conservation work must be based on:

- deeper knowledge of the "rules of the art" of ancient building;

- technical and scientific revision of the ancient constructive conception;

- $\quad$ effective anamnesis of the interventions carried out;

- $\quad$ effective diagnosis;

- $\quad$ systematic application of the principle of improvement;

- revision of many of the regulations contemplated by engineering in view of the specific requisites of the architectonic heritage;

- a reflective and critical use of the current headlong technological progress.

\section{References}

[1] Benvenuto E., An introduction to the History of Structural Mechanics, Springer Verlag: Berlin-New York 1991; Benvenuto E., La Scienza delle costruzioni e il suo sviluppo storico, Sansoni: Firenze 1981.

[2] Corsanego A., D’Agostino S., Vulnerability and Conservation Criteria of Archaelogic Complexes, Proceedings IX Europ. Conf. on Earthquake Engineering, Vol. 10-B, Moscow, pp.180-188, 1990.

[3] Le Goff J., Documento/Monumento, in Enciclopedia Einaudi, Torino 1978.

[4] D'Agostino S., Historical Buildings as an Archive of the Material History of Construction, in "Towards a History of Construction", BirkhauserVerlag: Genova 2002.

[5] D’Agostino S., "Historical Buildings as an Archive of the Material History of Construction", Atti Convegno dedicato a Edoardo Benvenuto "Towards a History of Construction" Genova 1999, Birkhauser-Verlag: pp. 369-376, 2002.

[6] Bellomo M., D'Agostino S., La Torre C., Giammarusti A.: "Seismic Vulnerability and Conservation of Historical and Archaeological Buildings: Italian Thoughts on Egyptian Architecture", Second Egyptian Conference on Earthquake Engineering - November 1-3 1997.

[7] Bellomo M., D'Agostino S., Improvements as a criterion for the antiseismic safeguarding and structural conservation of historical sites: methodology and examples, 12 WCEE, New Zeeland 2000.

[8] D.L. 29 Oct. 1999 n.490, Testo Unico delle disposizioni legislative in materia di beni culturali ed ambientali. 
[9] D’Agostino S., "La conservazione costruttiva dei Templi di Paestum” Atti Convegno Internazionale "Il restauro dei Templi di Poseidonia" Paestum 26-27 giugno 2004. In printing.

[10] D'Agostino S., Bellomo M., "Seismic vulnerability and structural preservation of the ancient city of Pompeii" XI European Conference on Earthquake Engineering, Balkema: Parigi 1998; D’Agostino S., Stendardo L., "La conservazione delle coperture in calcestruzzo armato nell'antica Pompei”, Atti XVI Convegno "Scienza e Beni Culturali. La Prova del Tempo", Arcadia Ricerche: Bressanone, XVI, pp. 287-296, 2000.

[11] D’Agostino S., Bellomo M., "The mausoleum of Cecilia Metella on the Appia Antica a Structural Contribution to its Restoration and Adaptation for Use", Atti $8^{\text {th }}$ Int. Conference "Structural Studies, Repairs and Maintenance of Heritage Architecture, STREMAH 2003, Halkidiki, Grecia, Brebbia Wit Press, pp. 461-468; Conforto M.L., D’Agostino S., "Extraordinary Maintenance Work Carried out on the Arch of Titus in Rome", Atti $8^{\text {th }}$ Int. Conference "Structural Studies, Repairs and Maintenance of Heritage Architecture, STREMAH 2003, Halkidiki, Grecia, Brebbia Wit Press, pp. 439-445.

[12] D’Agostino S., Migliore M.R., "Il restauro costruttivo del complesso Citroniera-Scuderia a Venaria Reale: gli aspetti strutturali", Convegno ARCo, Mantova, 30/11 - 2/12 2006. In printing.

[13] Settis S., Italia S.p.A., Einaudi: Torino 2002. 